\title{
Espelho Meu, Espelho Meu...
}

A primeira percepção pictórica do eu terá acontecido quando algum nosso ancestral se viu reflectido na superfície da água. É a própria mitologia a sugeri-lo, contando-nos que Narciso, de tanto se admirar no espelho líquido de uma fonte, acabou por se apaixonar por si mesmo.

Os primeiros espelhos produzidos pelo Homem terão aparecido na Anatólia (Turquia) há uns oito milénios; consistiam em obsidiana polida (material vítreo de origem vulcânica que contém 70-75\% de $\mathrm{SiO}_{2}$, sendo o resto $\mathrm{MgO}$ e $\mathrm{Fe}_{3} \mathrm{O}_{4}$ ). $\mathrm{O}$ corindo (uma das formas cristalinas do $\mathrm{Al}_{2} \mathrm{O}_{3}$, com vestígios de ferro, titânio e crómio e com grau nove na escala de dureza de Mohs - o grau dez, o máximo, é atribuído ao diamante) terá sido um dos materiais utilizados para o polimento da obsidiana.

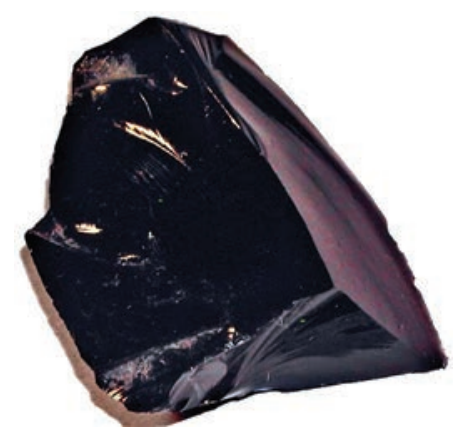

Obsidiana

Com o posterior desenvolvimento da técnica de extracção do cobre dos seus minérios e, mais tarde, da obtenção de bronze e de outras ligas, os metais passaram a ser usados no fabrico de espelhos, dos quais hoje se conhecem exemplares de cobre produzidos há 6000 anos nas regiões do vale do Tigre e do Eufrates, a sul da Mesopotâmia (actualmente Iraque). Posteriormente, o ouro e a prata foram igualmente usados na manufactura de espelhos, mais comummente para os folhear, aumentando a sua reflectância. A grande limitação destes espelhos era o facto de os fenómenos de oxidação atmosférica e de abrasão, aos poucos, os tornarem pouco fidedignos da realidade que reflectiam (a única excepção quanto à oxidação residia nos espelhos de ouro por este ser um metal demasiado inerte para escurecer por exposição ao ar). Uns dois milénios antes de Cristo os espelhos já eram mais ou menos utlizados em todas as regiões do globo onde se tivessem estabelecido sociedades com algum nível de civilização [1].

No Império Romano o fabrico de vidro e o uso deste estavam amplamente disseminados. Contudo, apesar das técnicas sofisticadas de que à época dispunham, os romanos não terão conseguido obter mais do que uns pequenos e grosseiros espelhos feitos à base de vidro e de chumbo. Com a queda do Império, a capacidade de produção no Ocidente de vidro transparente de boa qualidade decresceu acentuadamente.
Na Europa do século XIV, com uma indústria vidreira que lentamente recuperava dos reveses do passado, surgiram os espelhos convexos de vidro [2]. No célebre quadro de Jan van Eyck Retrato de Casamento do Casal Arnolfini, de 1434, aparece precisamente um desses espelhos em posição central, reflectindo toda a cena doméstica.

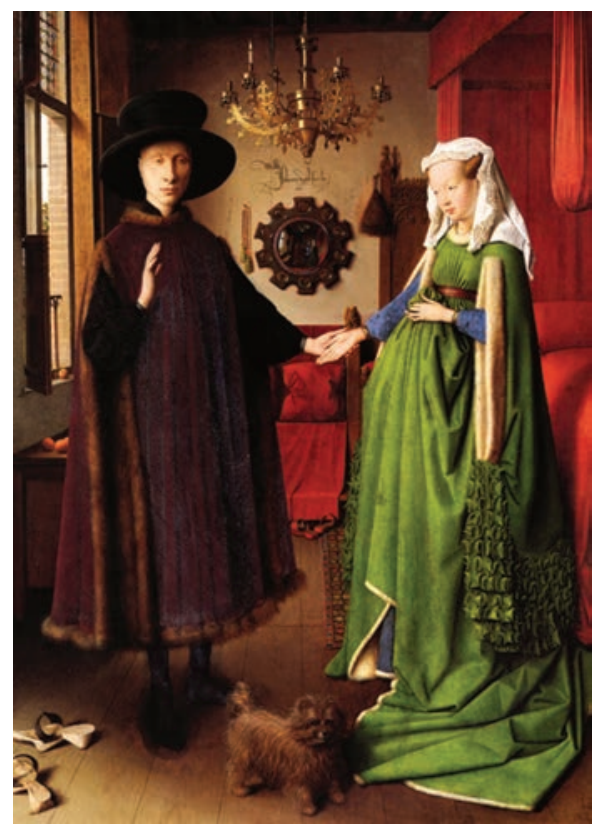

Retrato de Casamento do Casal Arnolfini (1434), Jan van Eyck (National Gallery, Londres)

A produção de espelhos era cara e laboriosa: um dos problemas era a areia usada no fabrico do vidro conter demasiadas impurezas para dela se poder obter um material límpido; para tornar tudo ainda mais complicado, era habitual o vidro estalar quando sobre ele se vertia o metal líquido.

Em Florença, na Renascença, foi inventado um processo de aplicação de chumbo a baixa temperatura sobre o vidro mas acabaram por ser os Venezianos de Murano, mestres ímpares na indústria vidreira, que criaram aqueles que podemos considerar os primeiros espelhos modernos. Para o efeito foi desenvolvida uma técnica que requeria a manipulação de largas quantidades de mercúrio líquido. Justamente da escola Veneziana, ficou-nos desse tempo uma das obras máximas da pintura europeia, a Vénus ao Espelho de Ticiano (ca. 1555), tela que retrata a esposa de Vulcano (o aleijado deus dos metais, do fogo e da metalurgia) olhando-se no espelho que Cupido - fruto de uma relação extraconjugal com Marte - lhe segura.

Atente-se na curiosidade de a tela Vénus e Marte surpreendidos por Vulcano, de Tintoretto (também Veneziano e da mesma época), representar Vénus a ser destapada por Vulcano, reflectido num espelho ao fundo, enquanto o pequeno Cupido dorme no berço e Marte se esconde debaixo da cama, tentando acalmar o cão que o pode denunciar. 


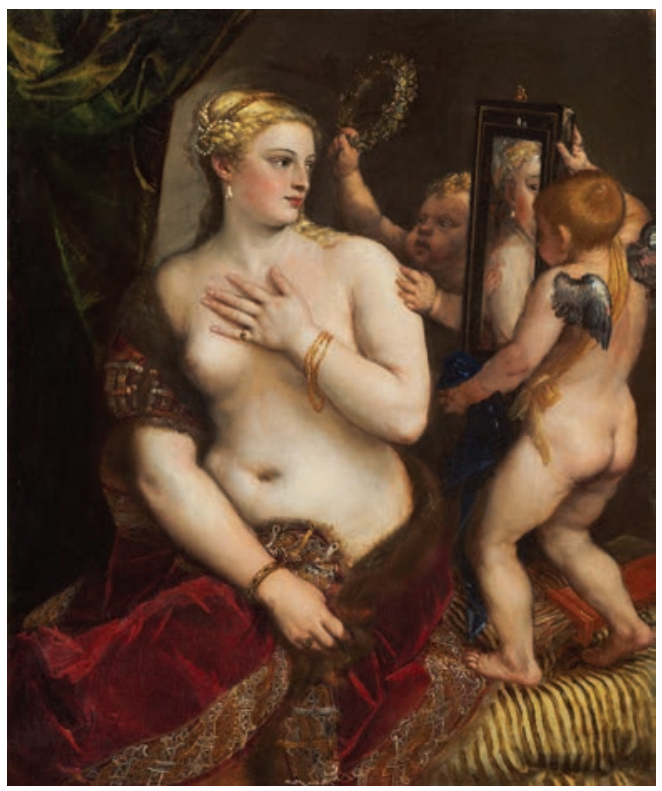

Vénus ao espelho (ca.1555), Ticiano (National Gallery of Art, Washington)

A técnica veneziana requeria que os artesãos espalhassem uma fina camada de folha de prata ou de estanho sobre uma superfície de mármore (a bancada em que a operação decorria), vertessem sobre ela o mercúrio (formando uma amálgama) e que colocassem de seguida o vidro por cima, certificando-se de que não ficavam bolhas de ar retidas entre este e os metais. Esta preparação era deixada em repouso durante algumas semanas.

Devido à grande toxicidade do mercúrio os artesãos acabavam por morrer bastante cedo. Dizia-se que nas cidades alemãs de Fürth e Nuremberga, que se tornaram dois grandes centros de manufactura de espelhos, os operários desta indústria não tinham um único dente nas gengivas - a queda dos dentes é um dos efeitos mais imediatos da intoxicação com mercúrio. Apesar de tudo, o impiedoso método de Veneza de fabrico de espelhos acabou por prevalecer por três séculos [3-4].

Num aparte refira-se que a primeira campanha contra a exposição ocupacional ao mercúrio surgiu em 1700, com a publicação da obra De Morbis Artificum Diatriba (As doenças dos Trabalhadores), da autoria do médico italiano Bernardino Ramazzini (1633-1714) que listou as então conhecidas ameaças à saúde encontradas em mais de cinco dezenas de profissões devido a produtos químicos, poeiras e metais (incluindo o mercúrio). Por essa razão, Ramazzini é hoje considerado o fundador da Medicina do Trabalho [4]. Ainda neste contexto valerá a pena mencionar que a deformação física atribuída ao mitológico Vulcano é entendida por muitos como o inevitável resultado da exposição ocupacional ao arsénio - semimetal de elevada toxicidade que aparece frequentemente associado aos minérios de cobre, ferro, chumbo e ouro.

Seria só no século XIX, com o trabalho de Justus von Liebig [5], que o método de fabrico dos espelhos acabaria por mudar. Tudo começou em 1835 quando o químico alemão

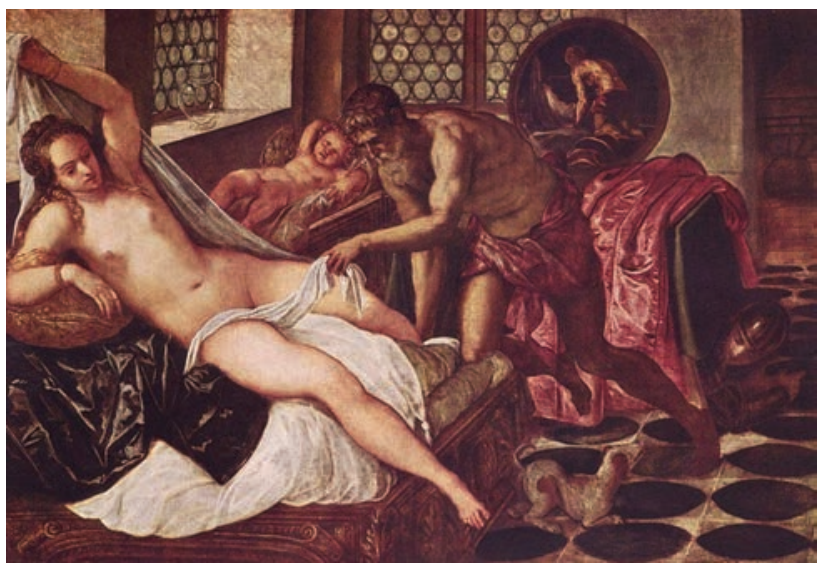

Vénus e Marte surpreendidos por Vulcano (ca. 1555), Tintoretto (Alte Pinakothek, Munique)

verificou que os aldeídos conseguiam reduzir os sais de prata a prata metálica. Esta reacçãofoi logo adoptada como teste de detecção da presença de aldeídos em materiais orgânicos.

Alguns anos depois, em 1843, o inglês Thomas Drayton patenteou um processo de pratear o vidro em que a película de prata se formava por adição de uma solução alcoólica de óleo de cássia a uma solução amoniacal de nitrato de prata. Embora a patente tenha atraído alguma atenção da indústria, o seu uso (que se restringiu à ornamentação de objectos de vidro de luxo) não prolongou para além da década de 1850, por ser comercialmente pouco viável.

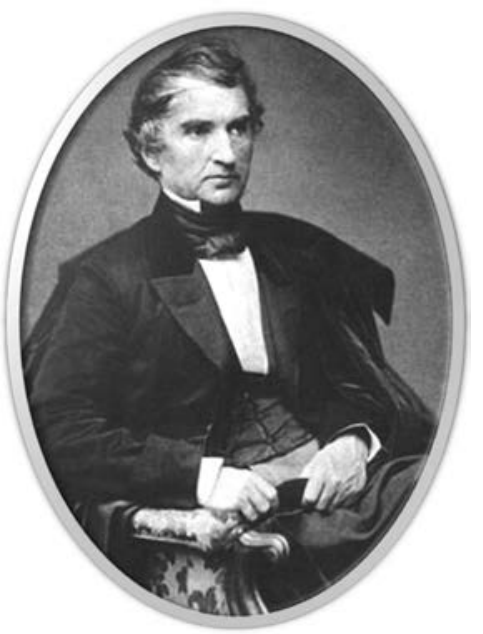

Justus von Liebig (1803-1873)

O estímulo que Liebig precisava para propor o fundamento do seu teste de detecção de aldeídos como base de uma nova técnica de manufactura de espelhos acabou por chegar em 1856, vindo de um amigo: o físico, astrónomo e fabricante de instrumentos científicos Carl von Steinheil (1801-1870). Este tentava desde 1847, sem sucesso, aperfeiçoar os espelhos planos dos telescópios; já tinha tentado o método de Drayton e trocado impressões com Rudolph Böttger (1806-1881), químico que desenvolvera métodos químicos e electroquímicos de deposição de películas metálicas sobrevários tipos de materiais, incluindo metais. 
Talvez inspirado pelos resultados deBöttger, Liebig verificou que se o vidro fosse previamente coberto com uma superfície de cobre por electrodeposição e só posteriormente mergulhado numa solução amoniacal de nitrato de prata e noutra de glucose (que na forma de cadeia aberta possui uma função aldeídica), a camada de prata obtida era perfeita, sem irregularidades. Liebig patenteou, nacional e internacionalmente, a sua descoberta mas o novo processo de fabrico de espelhos, apesar de alguns sucessos pontuais, não conseguiu competir economicamente com a indústria tradicional. Ironicamente, a invenção só se implantaria depois da morte de Liebig, em 1873, quando foi criada legislação na Alemanha proibindo o uso de mercúrio na manufactura de espelhos, abrindo assim portas à produção em massa dos espelhos modernos, sem recurso ao mercúrio. O espelho em segundo plano na tela de Édouard Manet Um Bar nas Folies-Bergère, de 1882, em que toda a cena se reflecte, poderá já ter sido fabricado de acordo com o novo método.

Os descendentes contemporâneos dos espelhos de Liebig já não contêm, porém, prata; este metal passou a ser substituído pelo alumínio, muito mais barato e igualmente com boas propriedades reflectoras. No processo de fabrico actual, o vidro é tapado de um dos lados e suspenso numa câmara de vácuo onde alumínio em pó é aquecido até à vaporização; em contacto com a superfície mais fria do vidro este condensa, formando uma fina folha de elevada reflectância [3,6].

Acresce registar que o método de Liebig não era completamente isento de problemas. Sendo o nitrato de amónio (composto explosivo) um dos produtos secundários da reacção de precipitação da prata, qualquer pequeno vestígio deste sal no espelho bastava para que, sob a acção de um agente de ignição (por exemplo calor), este se estilhaçasse.

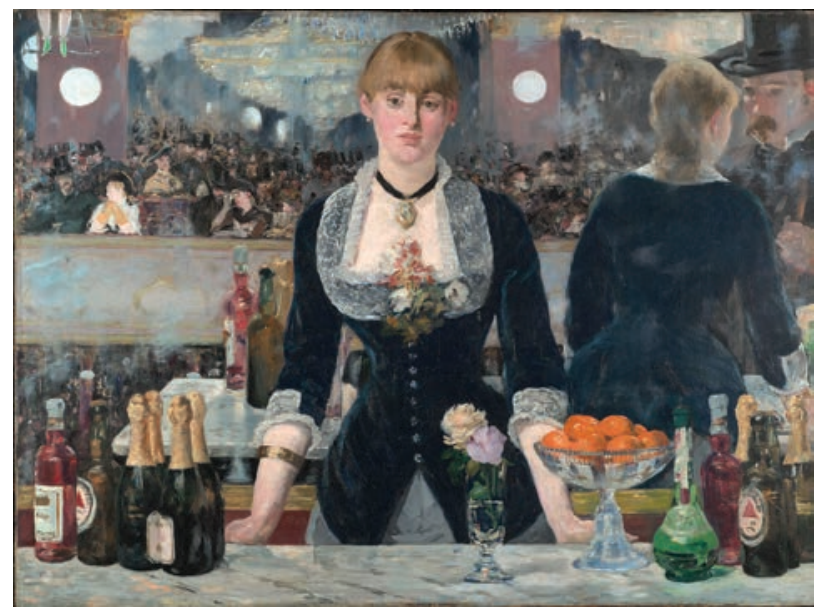

Um Bar nas Folies-Bergère (1882), Édouard Manet (The Courtauld Gallery, Londres)

Residirá aí o antigo dito de que "uma cara feia vista ao espelho o faz estilhaçar”?

\section{REFERÊNCIAS}

[1] J.M. Enoch, Optom. Vis. Sci. 83 (2006) 775-781

[2] http://cabinetmagazine.org/issues/14/mcelheny.php (acedido a 30/09/2014)

[3] W.H. Brock, “Justus von Liebig: The Chemical Gatekeeper”, Cambridge University Press, Nova Iorque, 1997

[4] J. Emsley, “The Elements of Murder - A History of Poison”, Oxford University press, Nova Iorque, 2005

[5] J.P. André, Química (Boletim da SPQ) 131 (2013) 52-53

[6] J. Schwarcz, "Is That fact? - Frauds, Quacks, and the Real Science of Everyday Life”, ECW Press, Toronto, 2014

João Paulo André

(jandre@quimica.uminho.pt)

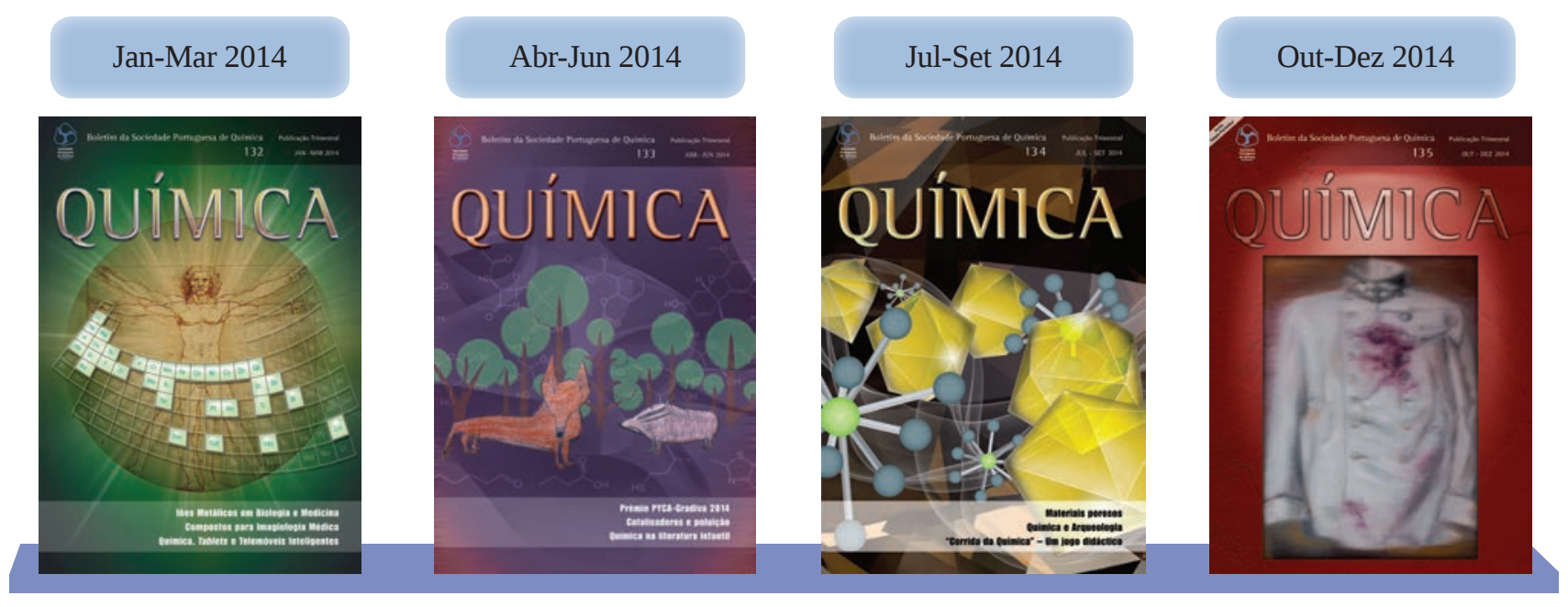

2014 foi assim ... fique para ver o que temos para si em 2015 ...

S P Q - SOCIEDADE PORTUGUESA DE QUÍMICA 